\title{
SENSORS AND POSITION CONTROL METHODS FOR PNEUMATIC SYSTEMS
}

\author{
Michail Papoutsidakis \\ Dept. of Industrial Design and \\ Production Engineering, \\ University of West Attica \\ Athens, Greece
}

\author{
V.J. De Negri \\ Dept. of Mechanical \\ Engineering, \\ Federal University of \\ Santa Catarina \\ Brazil
}

\author{
Avraam Chatzopoulos \\ Dept. of Industrial Design and \\ Production Engineering, \\ University of West Attica \\ Athens, Greece
}

\begin{abstract}
This research work contains information about modern controllers for pneumatic system and applications. To provide information in the most efficient way, ten different resources were examined and gained information is separated into two big parts: pneumatic controllers and control methods; and pneumatic positioning systems. In the first part there is described different pneumatic controllers and control methods for those systems also the same part includes information of comparing pneumatic controllers with digital controllers. The second part: pneumatic positioning systems examines two main groups of pneumatic positioning systems: open-loop and closedloop. This part gets into deeper view of each group and gives information about smaller sections of each group.
\end{abstract}

\section{INTRODUCTION}

Pneumatics is type of engineering that uses gas or pressurized air to achieve motion. Pneumatic systems are typically powered by compressed air or compressed inert gases. A controller is a device that collects an input signal from measured process variable, compares this value with predetermined one, and determines the appropriate amount of output signal required by the final control element to provide corrective action within a control loop. A pneumatic controller is a mechanical device designed to measure temperature or pressure and transmit a corrective air signal to the final control element. In this work there will be provided information about pneumatic systems controllers, control methods for pneumatic systems and pneumatic positioning systems.

\section{PNEUMATIC CONTROLLERS AND CONTROL METHODS}

Pneumatic controller is a mechanical device developed to always keep in process variables, for example pressure, temperature, flow rate, fluid level, etc. Pneumatic controllers collect that kind of data and transmit penitentiary air signal to the final control element. Pneumatic controller are powered by compressed air or natural gas and in most cases pressure is from 15 to $20 \mathrm{psig}$, though in very large systems can be used higher pressure. Because of robustness and suitability in hazardous places pneumatic controllers are often found in gas pipeline industrial equipment. In comparison there is possibility to use electric or electronic control system and they can be less costly than pneumatic system if only few control components are needed.

Approachable components of pneumatic controllers involve sensing elements, bellows, relays, transducers, actuators, flapper nozzle amplifier. Figure [1] is representing example of simple pneumatic control system where the flow of water through a pipe has kept constant at some established value. Flow transducer measure actual water current. After that flow rate is comparing with desired current. Difference between these values is called error. If there is error, the pneumatic controller is sending signal to actuator which is pressing or releasing valve until the required flow is reached.

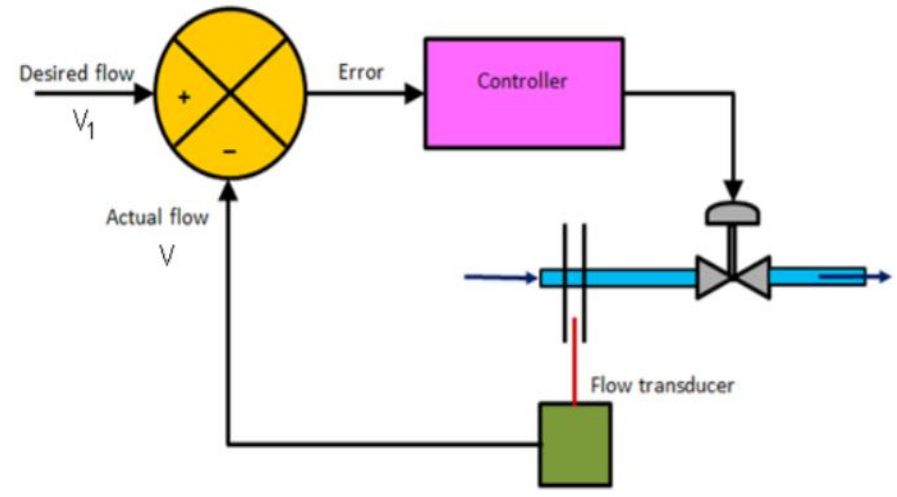

Fig. 1. Pneumatic Control System

One of the general component of pneumatic control system is the flapper nozzle amplifier or also can be called bleed- type controller. This element can convert very small displacement signal of change of air pressure. Figure [2] represents general construction of flapper nozzle amplifier. The air supply constantly flows to one end of the pipeline which is making permanence air pressure. At the same side there is orifice. At 


\section{International Journal of Engineering Applied Sciences and Technology, 2019 \\ Vol. 4, Issue 5, ISSN No. 2455-2143, Pages 478-485 \\ Published Online September 2019 in IJEAST (http://www.ijeast.com)}

the other end of pipeline there is nozzle and a flapper. Gap between nozzle and flapper defines by the input signal. Air flow through the nozzle depends on how close flapper is. When the flapper moves closer to the nozzle, the amount of air which flows through the nozzle will decrease and air pressure inside the pipe will increase. In other scenario, air pressure will decrease if flapper recede from nozzle.

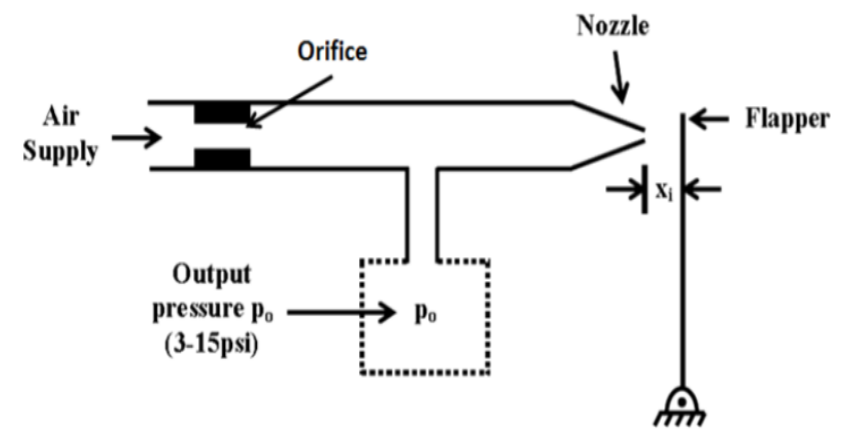

Fig. 2. Nozzle Flapper Amplifier

The main issue of flapper nozzle amplifier is limited air handling capacity. It cannot be useful unless air handling capacity is increased. To increase the volume of air to be handle is using air relay. Figure [3] explains the principle of operation of an air relay. Air relay is directly connected to the supply line and the output pressure of flapper nozzle amplifier (p2) is connected to lower chamber. Lower chamber is filled with diaphragm which movement causes output pressure (p2) amount. On top of diaphragm there is double-seated valve which blocks air vent when the nozzle pressure increases, because flapper moves closer and pressure through nozzle decrease. On the other hand if more air goes through nozzle then output pressure (p2) decrease, the diaphragm moves downwards and for that reason double-seated valve blocks air supply line and connects output port to the vent.

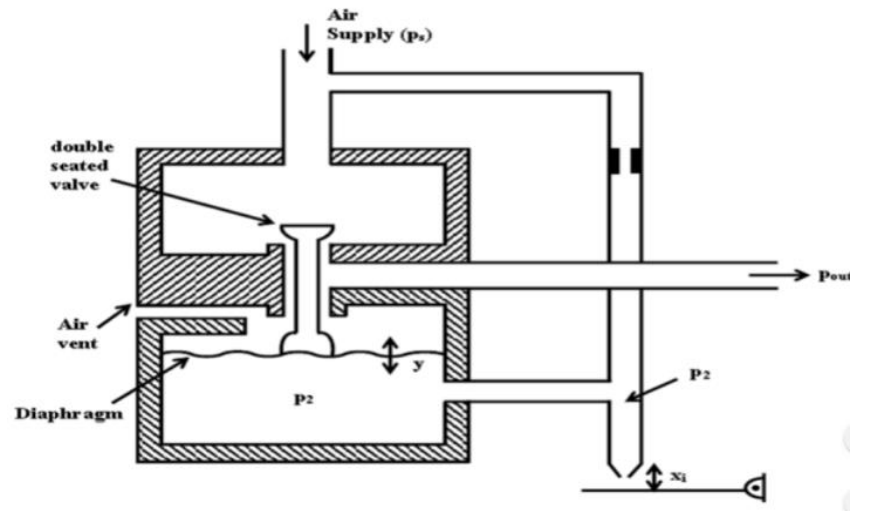

Fig. 3. Air relay

Pneumatic controllers have different types. The simplest type of controller is called proportional controller. Figure [4] shows overall arrangement of pneumatic proportional controller. The system consisting pneumatic components such as air relay, flapper nozzle amplifier, bellows and springs.

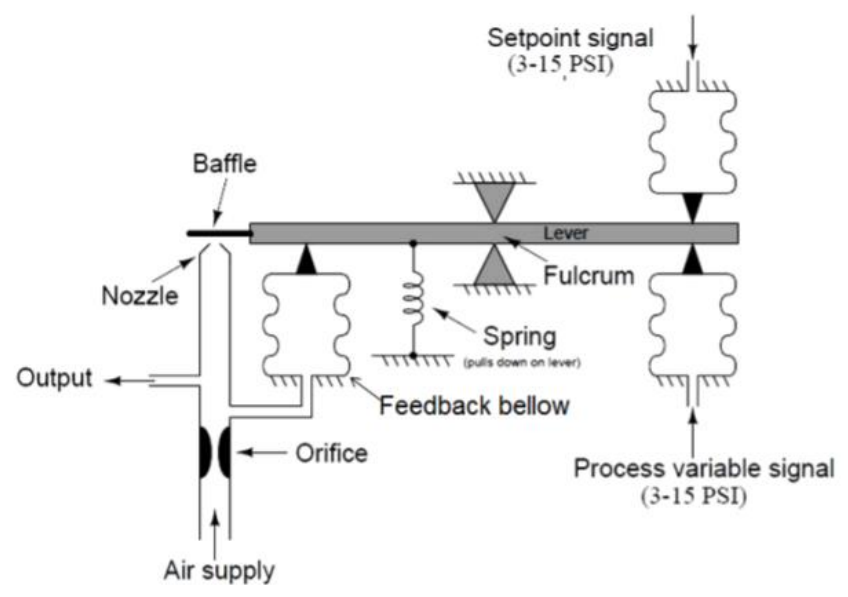

Fig. 4. Proportional Controller Elements

Proportional controller acts in pneumatic system and making output pressure and displacement proportional. Figure [5] explains operating principle of similar proportional controller. (A) In the moment when the control port is open, the exhaust valve which is between the control and exhaust chamber is open. Thus, air in the control chamber equals to atmospheric pressure. Because of supply pressure, spring closes supply valve. (B) Pilot chamber pressure begins to rise, when sensing component moves closer to control port. When the pressure in pilot chamber reaches 3 psi, pressure overcomes the force of spring and closes the exhaust valve. (C) Because of increasing pilot pressure pilot diaphragm moves down and opens the supply port. Thus that makes supply air to freely pass to control line. (D) When the pressure increases in control chamber, then it acts against the control diaphragm to oppose pilot pressure. After that when all of forces in every direction is equal, the supply valve is closed and the system is balanced. 

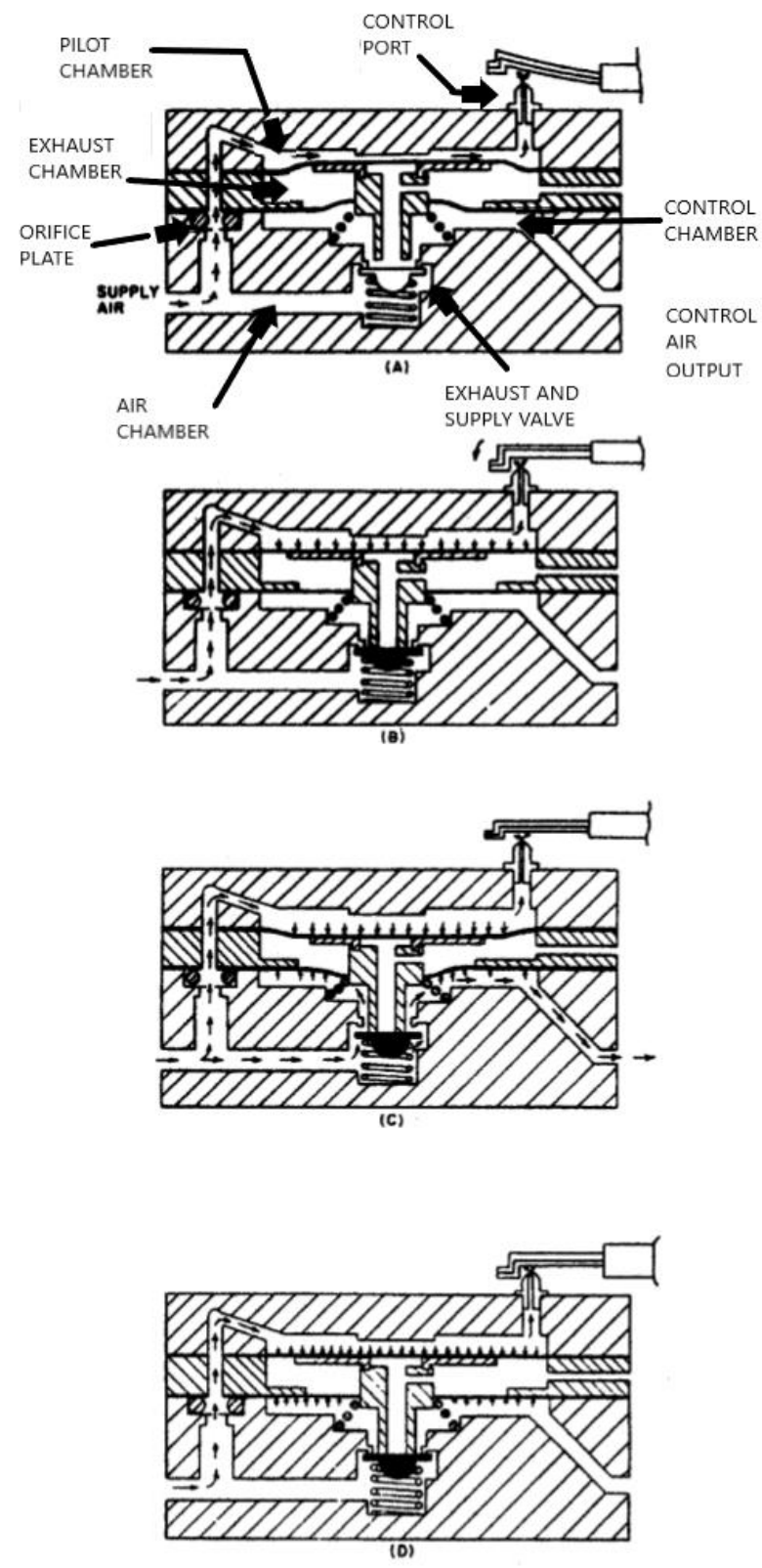

Fig. 5. Operation of Proportional Controller

Another quite similar pneumatic controller is called twoposition controller. Main differences between proportional and two-position controllers are valve and spring arrangement. Figure [6] demonstrates main part of two-position controller.

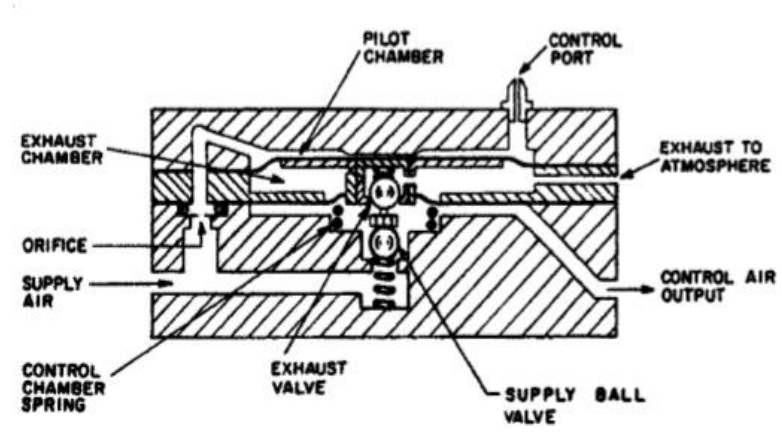

Fig. 6. Two-position Controller

Figure [7] describes operation of a two-position controller. (A) In the moment when the control port is open, through the supply hole flows air and it goes to supply chamber and out the control chamber. Air pressure force spring to hold the supply ball valve open and the exhaust valve closed. (B) Because control port is closed, pressure in the pilot chamber rises. In the moment when pilot pressure become greater than opposing forces, the pilot diaphragm moves and presses the supply ball valve. (C) Finally the pilot diaphragm opens the exhaust ball valve, thus the air from control chamber is released to atmosphere. This action decreases forces resisting the pilot pressure and become a reason to fully open exhaust valve and stay open until pilot pressure is reduced. After that the actions sequence is reversed.

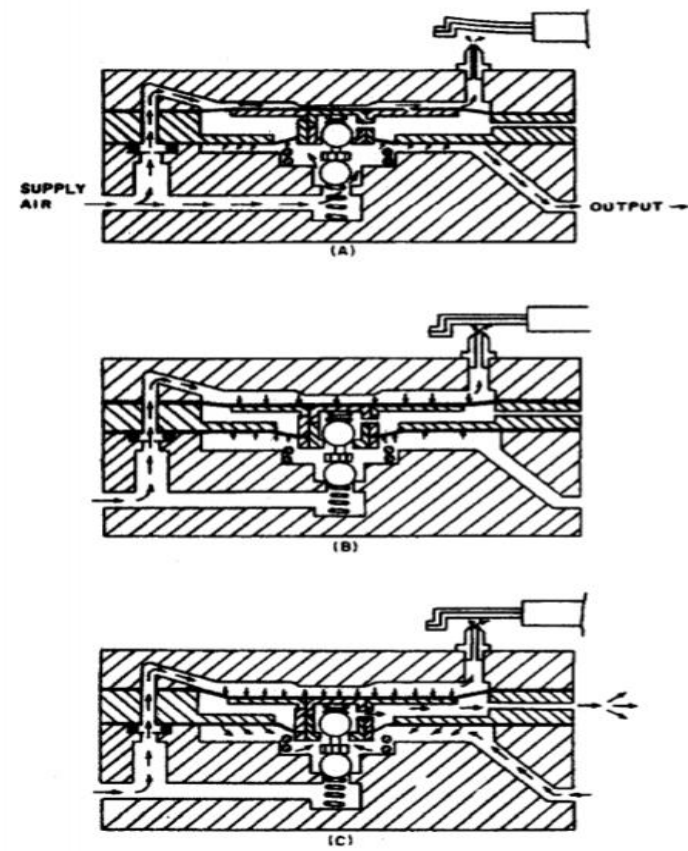

Fig. 7. Operation of Two-position Controller 


\section{International Journal of Engineering Applied Sciences and Technology, 2019 \\ Vol. 4, Issue 5, ISSN No. 2455-2143, Pages 478-485 \\ Published Online September 2019 in IJEAST (http://www.ijeast.com)}

\section{A. Sensing elements in pneumatic controllers}

There are three main sensing elements which are using in sensor-controlled systems:

- Temperature sensing element

- Pressure sensing element

- Humidity sensing element

a) Temperature sensing element

There are various temperature sensing elements for example bimetal elements, bellows, liquid, gas refrigerant filed bulb and capillary sensors. But one of the simplest is bimetal element. That kind of element includes two strips of different metals. Those metals are combined together. Reason for two dissimilar metal is that they expand in different temperature rates. When the temperature changes the metal bends. The bended metal position can vary the pressure of pneumatic controller. The most efficient to use one metal which has high coefficient of expansion, for example brass, and the another metal or alloy that has low expansion coefficient. Figure [8] show how bimetal element works in the moment when is heated.

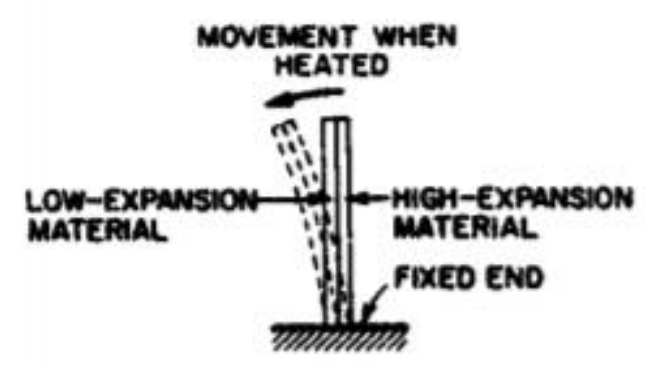

Fig. 8. Bimetal Sensor

b) Pressure sensing elements

Different pressure sensing elements can include diaphragms, bourdon tubes and bellows. In practice bourdon tubes used the most. Figure [9] shows movement of bourdon tube sensor. The sensor has flattened tube which is bent to circular form. One end of the tube is connect to pressure source or vacuum and other end of tube is connected to some linkage, but can move freely. When the pressure become higher, the tube tries to straight out and that kind of movement through linkage transfers motion to gear. Overall this sensor can indicate position or actuate a controller.

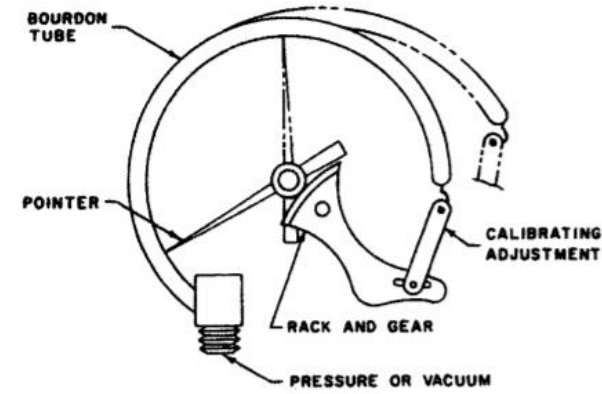

Fig. 9. Bourdon Tube

c) Humidity sensing elements

Mostly humidity sensing elements are made of hygroscopic materials. Those kind of materials act and hold water molecules from surrounding environment and change size when humidity is changed. Humidity sensing elements generally are made from two woods. The most commonly are used cedar and yew woods. The working principle is similar to bimetal sensor instead of temperature changes it bends as humidity changes.

Main advantages of pneumatic controllers is:

- $\quad$ Safe to use in hazardous places

- $\quad$ Easy to maintain

- Low cost of installation

- Steady response

There is also some disadvantages:

- Leaking air

- Slow response

- Hard to operate in subnormal temperatures.

\section{$B$. Digital and pneumatic control}

Because of disadvantages of pneumatic controllers and benefits of electronic controllers nowadays industry companies are choosing digital control. It is evident that digital controllers have capabilities for custom control logic and communication also for process tuning. Another main reason why companies are looking for digital controllers that because pneumatic equipment prices have increased and main pneumatic suppliers decided to stop many product lines. But on the other hand there are many companies that still using pneumatic controllers in the gas pipeline industry. The main reason why gas pipelines are still using pneumatic controllers because there is always pressurized gas that runs the controller, thus there is no need for additional power source. 


\section{International Journal of Engineering Applied Sciences and Technology, 2019 \\ Vol. 4, Issue 5, ISSN No. 2455-2143, Pages 478-485 \\ Published Online September 2019 in IJEAST (http://www.ijeast.com)}

Another reason that pneumatic controller unlike digital controllers cannot be affected by lightning, thus it cannot start fire.

Table [I] compares most basic control functions between pneumatic and digital controllers.

Table -1

\begin{tabular}{|c|c|c|}
\hline Function & $\begin{array}{l}\text { Pneumatic } \\
\text { controller }\end{array}$ & $\begin{array}{c}\text { Digital } \\
\text { controller }\end{array}$ \\
\hline Controlling & $\begin{array}{l}\text { Uses pressure } \\
\text { or flow, but } \\
\text { changing } \\
\text { needs } \\
\text { hardware } \\
\text { change }\end{array}$ & $\begin{array}{c}\text { Uses pressure } \\
\text { or flow, and } \\
\text { can be } \\
\text { changed via } \\
\text { software }\end{array}$ \\
\hline Power source & $\begin{array}{c}\text { Pressurized } \\
\text { air or gas }\end{array}$ & $\begin{array}{l}\text { External } \\
\text { electric } \\
\text { power }\end{array}$ \\
\hline $\begin{array}{c}\text { Eligibility for } \\
\text { hazardous } \\
\text { environment }\end{array}$ & $\begin{array}{l}\text { Cannot be } \\
\text { ignited }\end{array}$ & $\begin{array}{c}\text { Requires } \\
\text { additional } \\
\text { devices in } \\
\text { order to use }\end{array}$ \\
\hline Robustness & $\begin{array}{l}\text { Cannot be } \\
\text { damaged by } \\
\text { electrical } \\
\text { disturbances }\end{array}$ & $\begin{array}{c}\text { Can loss } \\
\text { power or be } \\
\text { damaged by } \\
\text { electrical } \\
\text { disturbances }\end{array}$ \\
\hline $\begin{array}{c}\text { Remote } \\
\text { access }\end{array}$ & $\begin{array}{l}\text { Impossible to } \\
\text { access unless } \\
\text { there is } \\
\text { electronic } \\
\text { sensors }\end{array}$ & Easy to access \\
\hline
\end{tabular}

\section{Summary}

Pneumatic controllers can be very useful in hazardous environmental because they not require external electrical power source and cannot be ignited. On the other hand pneumatic controllers are old technology and nowadays more suitable are digital controllers because of benefits such as easy control, remote access and etc.

\section{Pneumatic Positioning Systems}

Pneumatic positioning systems are mostly found in robotic and manipulator systems, welding and riveting machines, pick and place devices, vehicles and etc.

\section{A. Open loop pneumatic positioning systems}

There are two main groups of pneumatic positioning controlling: open and closed loop positioning control. Usually the main criteria which distinguishes open-loop and closed loop pneumatic positioning control is that open loop pneumatic positioning actuator contains hard mechanical stops. To get into deeper view of open loop system, it has two covers in a pneumatic cylinder which makes hard mechanical stops that determine stop positions. Figure [10] demonstrates schematic view of such an actuator. This diagram shows aircushioning mechanism which is provided by a piston (1, Figure [10]) with two cylindrical parts (2 and 3) which has two cover cavities (4 and 5). According to the control algorithm the solenoid control valve (6) connects the pneumatic cylinder to the supply pressure and exhaust port. The maximum value of the piston velocity is defined by adjustable throttles (7 and 8). A noncontact indication of cylinder piston position is provided by two permanent magnets (9 and 10) included in the piston and two proximity sensors (11 and 12) attached to the outside of the cylinder tube. Sensors indicate a cylinder position without contact. When the piston is moving from one side to another, the switch closes by the magnetic field, this completes electrical circuit and produces an electrical signal.

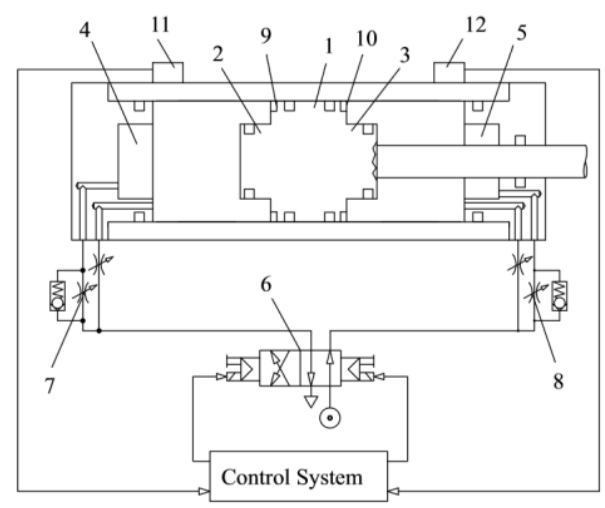

Fig. 10. Block Diagram of the Pneumatic Cylinder with two Positioning Stops on the Ends

The main idea of the air cushioning is to reduce deceleration to a decent level. This is achieved when cushioning air absorb and dissipate the impact kinetic energy. Such working principle can be seen in the pneumatic system if the piston speed is above $0.2 \mathrm{~m} / \mathrm{s}$. Linear and radial moving of the cushion seals has two main benefits of using it. First, it solve the misalignment problem. And the second big advantage of using air cushioning is that it minimalizes the noise pollution which is harmful for workers and environment.

\section{B. Controlling of neumatic actuator with two variable hard stops}

Figure 11 demonstrate the pneumatic actuator with two variable hard stops. It is used to stop the piston in the two variable position points within the whole piston stroke. The structure and the working principle of this system is similar to the one shown in Figure 10. The main difference is that to stop 


\section{International Journal of Engineering Applied Sciences and Technology, 2019 \\ Vol. 4, Issue 5, ISSN No. 2455-2143, Pages 478-485 \\ Published Online September 2019 in IJEAST (http://www.ijeast.com)}

piston is used shock absorbers instead of the air cushions. This design provides piston speed in range from 2 to $3 \mathrm{~m} / \mathrm{s}$ and position stationarity in up to $0.01 \mathrm{~mm}$. The main drawback of such actuator is poor applicability because stopping points are moved by hand, they are not programmable.

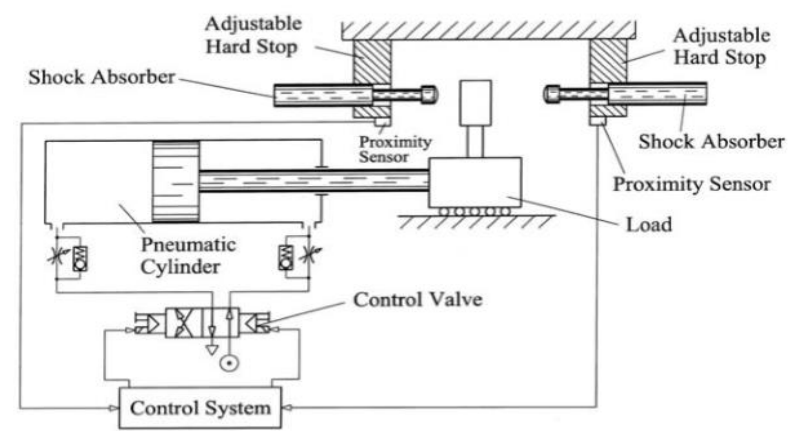

Fig. 11. Schematic Diagram of the Pneumatic Positioning Actuator with two Variable Hard Stops

To design shock absorber system there is necessary to evaluate such criteria:

- The velocity of the cylinder

- The mass being moved

- The external forces acting on the system

- The system pressure

- The piston diameter

\section{Pneumatic positioning system with multiposition pneumatic cylinder}

Another Pneumatic positioning systems uses multiposition pneumatic cylinder. This is open-loop system which usually consists of two or three connected cylinders. Figure 12 demonstrate this type actuator with three pneumatic cylinders, which has four positioning points. The number of positioning points in this type of pneumatic positioning system is always one more then there is connected pneumatic cylinders. Each cylinder have the rod which is mechanical hard stop for the sequential piston. For example in the case shown in Figure 12, the two left pistons with their rods create the hard stop for the right piston. Although the design of the actuator is simple and provides high reliability, it has impacts during the stopping which can disturb the fluent work of the positioning. Also in a number of case, this type of system is massive because of the big amount of the control solenoid valves.

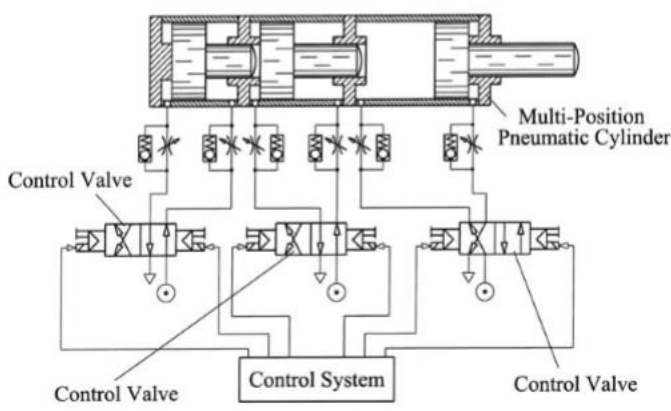

Fig. 12. Schematic Diagram of the Actuator with Multi-positioning Cylinder

\section{$D$. Closed loop pneumatic positioning systems}

The other group of pneumatic positioning actuators is closed loop. This type of actuators have a transducer which measures and converts the actuator output signal to an electrical signal. Then the command signal is compared with converted feedback signal and the resulting error signal is sent to achieve the proper position. For closed loop pneumatic positioning systems there is mainly used two types of technologies: airflow regulation using servo or proportional control valves and a braking mechanism.

\section{E. Positioning system with servo or proportional control valves}

Figure 13 shows pneumatic positioning systems with direct acting proportional control of air pressure. This invention includes control electronics with a range of standard pneumatic valves, cylinders and actuators. It uses direct acting proportional pressure regulators to continually check and adjust pneumatic pressure. This change is enough to ensure precise control of cylinder positioning. The electro pneumatic positioning system has two proportional pressure regulators one on either side of the pneumatic cylinder piston. On the one side pressure regulator keeps a fixed pressure and on the other side pressure is controlled by other proportional pressure regulator. The systems controller compares data of the pressure sensors on both sides of cylinder and give command signals to proportional pressure regulators. Using this simple scheme piston are moved to that side where the pressure is lower. 


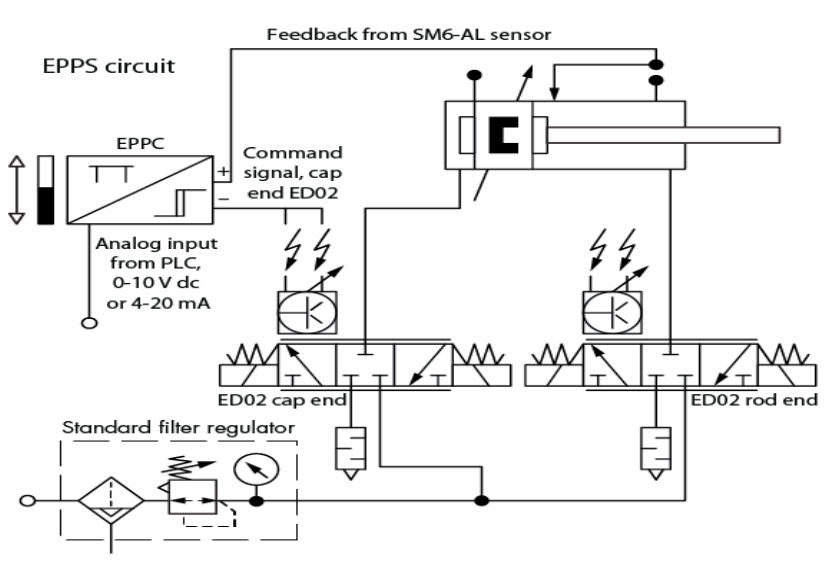

Fig. 13. Electro Pneumatic Positioning System Schematic

Advantage of such kind method is increased accuracy. Effects of piston slightly moving forward and backwards is eliminated due to that fact that proportional pressure regulators constantly monitors the pressure. Also this kind of system can control pressure within very narrow range that means that if actuators are chosen correctly and tuning of the controller is optimized the system can reach $\pm 1 \mathrm{~mm}$ positioning accuracy.

To achieve high speed and accurate actuator movement valve should quickly and responsibly act to commands from the control system. When the pneumatic cylinder reaches the desired position, the valve shifts over center according to the internal algorithms to build up pressure for smooth deceleration to the set point with the necessary dynamic characteristics.

The biggest role in the positioning servo pneumatics working process play the control algorithms. In this closed loop system, acceleration and velocity are controlled using three loop position feedback. The controller adds three signals which include: cylinder position gained directly from the position sensor, velocity and acceleration derived from position vector and from those three different signals it generates the correction signal to the valve.

A practical point of view is that any servo system must be tuned. In this case, to achieve stable operation control system evaluates baseline loop characteristics such as control valve, cylinder, payload and motion parameters. Also to optimize performance the adaptive control algorithms evaluate the quality of motion after every cycle. So system is capable to adapt to payload changes or seal and bearing characteristics change with use.

\section{F. Pneumatic positioning system with braking mechanism}

Other technology in closed loop positioning system is braking mechanism. This type of actuator usually uses a pneumatically driven external mechanical brake with spring loaded friction pads which acts typically on the rod of the pneumatic actuator. Usually the brake is activated by increased air pressure. In pneumatic braking systems positioning is achieved by applying the pneumatic brakes at a predetermined point in case to reach the target position. Figure 14 demonstrate the schematic view of such a positioning actuator.

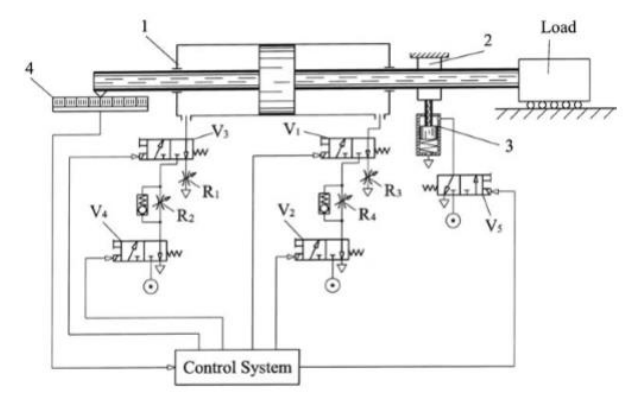

Fig. 14. Positioning Actuator with Pneumatic Brake

1 - Pneumatic cylinder

2 - Mechanical brake

3 - Pneumatic cylinder which drives mechanical brake

4 - Positioning sensor

5 - Valve controlling the pneumatic brake cylinder

V1 - V4 - Load displacement valves

R1 - R4 - Throttles

Pneumatic cylinder is controlled by four valves which are arranged in pair series. It allows to achieve independent adjustment of high speed $\mathrm{xm}$ and low speed $\mathrm{xc}$ of the load. Four throttles perform those adjustments. The positioning process has two stages. At the first stage, the load speed is reduced by pneumatic means and at the second stage the mechanical brake is applied to the rod and it holds the load to the desired position. Figure 15 demonstrate an usual velocity curve for this positioning process and the control algorithm for this actuator, which is demonstrated in Table II. Here, load position $-\mathrm{x}$; velocity $-\dot{\mathrm{x}}$; Vi determines the valve's state (i is valve number: 1 - valve is energized, solenoid action; 0 valve is deenergized, spring action); coordinate of the positioning point $-\mathrm{xd}$; $\mathrm{x} 1$ is the distance from the positioning point where the cylinder starts to change the velocity from $\dot{x} m$ to $\dot{\mathrm{x}}$; and $\mathrm{x} 2$ is the distance from the positioning point where the brake is switched on.

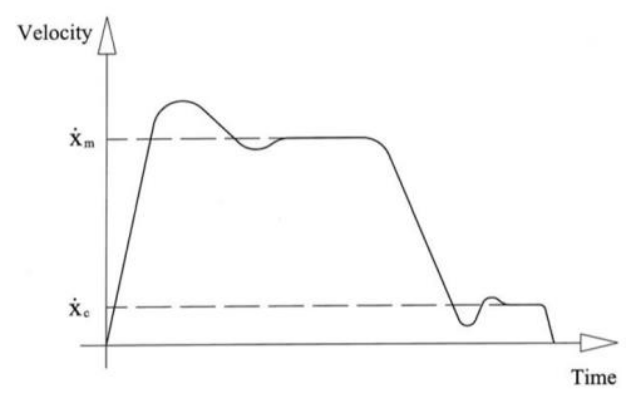

Fig. 15. Velocity Changing Curve 
Table II. Control algorithm

\begin{tabular}{lccccc}
\hline$x$ & $V_{i}$ & $\dot{x}$ & $x$ & $V_{i}$ & $\dot{x}$ \\
\hline$x \leq x_{d}-x_{1}$ & 00111 & $\dot{x}_{m}$ & $x \geq x_{d}+x_{1}$ & 11001 & $-\dot{x}_{m}$ \\
$x_{d}-x_{1}<x<x_{d}-x_{2}$ & 00111 & $\dot{x}_{c}$ & $x_{d}+x_{2}<x<x_{d}+x_{1}$ & 11101 & $-\dot{x}_{c}$ \\
$x \leq x_{d}-x_{2}$ & 11110 & 0 & $x \leq x_{d}+x_{2}$ & 11110 & 0 \\
\hline
\end{tabular}

Pressure variation, brake-pad wear, variation of the brake switching time, and the friction force in the pneumatic cylinder makes system tuning to work. Typically, the $\mathrm{x} 1$ value remains the same in all working process, it is not depending of any variation in the actuator operating conditions. The nature of the transitional process is the main criterion in $\mathrm{x} 1$ value selection to achieve insignificant low speed $\mathrm{xc}$ variation before approaching the position $x$. To compensate the influence of variation in operation conditions of the actuator the $\mathrm{x} 2$ value is changed.

\section{$G$. Pneumatic positioning system with magnetorheological braking device}

Another positioning actuator uses magnetorheological braking devices placed in parallel with pneumatic cylinder. Magnetorheological braking devices is based on magnetorheological fluids which has ability to reversibly change from free flowing liquid to a semisolid with controllable yield strength in milliseconds when magnetic field is applied.

Magnetorheological brakes according to the applied current proportionally creates a braking force. Accurate and robust motion control is achieved through closed loop feedback of the positioning sensor. Figure 16 demonstrate the schematic diagram of such a positioning actuator. To guarantee that the cylinder is directed toward the desired position the three position solenoid control valve takes action. The magnetorheological brake is capable enough to stop the pneumatic cylinder. This gives the full control with the ability to adjust a broad dynamic range of velocity control.

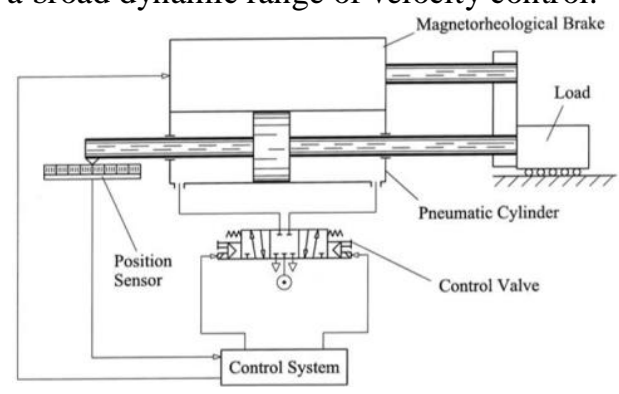

Fig. 16.

Positioning Actuator with Magnetorheological Brake

Pneumatic control algorithm logic is simple Boolean logic based on the sign of the position error. According to this logic the valve stay to its neutral position when position $\mathrm{x}$ is within the tolerance band $(\Delta)$. When position $\mathrm{x}$ is within $\Delta$ the logic commands for magnetorheological braking is given in step wise or progressive braking. To provide an estimation of system velocity the position is differentiated. System velocity is the main criteria for an error function that passes through a controller. This signal is summed with the magnetorheological braking signal to provide constant velocity control.

\section{H. Summary}

Pneumatic positioning systems are based on two main groups. Open and closed loop. Open loop systems are quite simple and usable if only there is needed a few constant stopping points, but they are poorly adaptive if there is needed to change a stopping positions. Closed loop systems are more adaptive to such changes. It also evaluate changes which appear during the systems use, so it can provide more accurate moving and stopping positions.

\section{ACKNOWLEDGMENTS}

All authors would like to thank the University of West Attica for the financial support provided to them for this research project.

\section{REFERENCES}

[1] R. W Haines, D. C Hittle "Control Systems for Heating, Ventilating and Air Conditioning” Springer, pp. 366, 2003.

[2] I. L. Krivts, G. V. Krenjnin "Pneumatic Actuating Systems for Automatic Equipment" Taylor \& Francis Group, LLC, pp. 335, 2006.

[3] B. Dehgham „Position Control of a Pneumatic System Using Adaptive Intelligent Methods“ Queen`s University, pp. 160, June 2012.

[4] D. Waller, H. Werner „Pneumatics Workbook Basic Level“"Festo Didactic GmbH \& CO, pp 194, 2002.

[5] K. E Rydberg "Basic Theory for Pneumatic System Design" Linkoping university, pp. 34, 1997.

[6] N. Franklin "Basic Pneumatics” Rev. 0100, pp 120, 1997.

[7] P. Croser, F. Ebel "Pneumatics Basic Level”, Denkendorf, pp 51, 2002.

[8] S. Vincent, J. Bridges, "Positioning with air", 2015.

[9] NPTEL, "Mechatronics and Manufacturing Automation, 2014.

[10] C. Wilson, "Digital vs Pneumatic Control”, 20014. 